\title{
How to Enhance Employee Voice Behavior Based on Game Theory
}

\author{
Manzhen Tang \\ Jinan University Management School, Guangzhou, China \\ Email: tangmanzhen@163.com
}

Received 23 February 2015; accepted 15 March 2015; published 18 March 2015

Copyright (C) 2015 by author and Scientific Research Publishing Inc.

This work is licensed under the Creative Commons Attribution International License (CC BY). http://creativecommons.org/licenses/by/4.0/

(c) (i) Open Access

\begin{abstract}
With the need of enterprise competition and development, the importance of the employee voice behavior is becoming increasingly apparent. Therefore, people pay more and more attention to employee voice behavior in the field of organization behavior. From the perspective of game theory, this paper has established a static game of complete information and analyzed the strategy selection between enterprise and the employee. Meanwhile, we take appropriate measures in order to achieve win-win development of enterprises and employees.
\end{abstract}

\section{Keywords}

Employee Voice Behavior, Static Game of Complete Information, Voicing Mechanism

\section{Introduction}

In view of need of enterprise competition and development, the importance of the employee voice behavior is becoming more and more apparent. Employee voice behavior, as one of effective ways of management, is approved by many researchers and entrepreneurs.

Employee voice as informal and discretionary communication by an employee of ideas, suggestions, concerns, information about problems, or opinions about work-related issues to persons who might be able to take appropriate action, with the intent to bring about improvement or change [1]-[3]. As the definition highlights, the content of the message can vary widely, from ideas for how to do things differently to information about serious or potentially serious problems. Organizations inevitably need their employees' ideas and thoughts to speed innovation and enhance organizational effectiveness, which in return improves organizational flexibility, realizing innovative and sustainable development. Employees are regarded as major sources of change, creativity, learning, and innovation, which are critical factors to the success of organizations. So an increasing number of researchers turn their attention to the cause of employee voice and model of action. 


\section{Theoretical Background}

In the 1970s, Employee voice behavior was studied by the economist Hirschman, at the earliest. In his "EVL" model, he treated "exit", "voice” and "loyalty" as three kinds of reactive model organization members may adopt, when the organization is in declining stage. Voice is the way to express employee's dissatisfaction to management. Staff that has high-loyalty to the enterprise would choose voice, instead of relieving guard or dismission. In 1988, Rusbult et al. came up with "EVLN" model, which based on "EVL” model, and they regard "exit”, voice", "loyalty" and "neglect” as behavior reaction in which employees show their discontent with their work. In their model, Exit is an initiative constructive behavior; Voice is an initiative construction behavior; Loyalty is a passive constructive behavior and Neglect is a passive destructive behavior. Expanding on work by Van Dyne et al., Van Dyne \& LePine [2] introduced the term voice to the extra-role behavior literature and demonstrated its conceptual and empirical distinctiveness both from in-role behavior and from more cooperative and non-challenging forms of extra-role behavior such as helping others.

The employee could choose to engage in voice if he or she is sufficiently motivated and able to do so. However, many employees choose not to voice their opinions and concerns about matters in their organizations. While in a changing world, organizations need employees to express their ideas. Researchers attempted to analyze the influence factors of voice from different angles, but certain aspects of the process have been more explicit than others. The first one is employee's personality; researchers discussed the relationship between personality, psychological control and employee voice based on psychological theory. Some studies back up the factor of OCEAN (i.e., extraversion, neuroticism, openness agreeableness and conscientiousness), and it showed employees who are extraversion and conscientiousness have more voice, and the neuroticism has less voice [2] [4]. In addition, a central theme in the literature is that voice is often perceived to be risky. Employees may concern that sharing their views or concerns will upset others or cause others suffer from negative repercussions. There are many reasons why employees may believe that voice to have such risks, particularly in the case of prohibitive voice, which is focused on problems or sensitive topics [5]. Even managers who sincerely wish to be open to employees' ideas and concerns may feel vulnerable or threatened by input from below that is critical of existing policies or practices [6], so it is perhaps not surprising that studies have found employees to be more likely to engage in voice when they have a greater sense of psychological safety and more likely to remain silent when they perceive voice to be unsafe [3] [6]. There is also a recent study showing that silence is less likely when organizations have caring climates, which encourage benevolence and prosaically behavior, and more likely when organizations have instrumental climates, which encourage self-interest [7].

There are many studies have been done on the game theory analysis of employee voice behavior. Wang [8] introduced the one-time dynamic game model and repeated games model, he analyzed the selecting strategy of employer and employee in the progress of voice behavior. A prisoner's dilemma problem with employee voice arrangements in Liberal Market Economies, Freeman and Lazear [9] suggest that employee voice and participation institutions require a semblance of power equilibrium if workers are to share discretionary knowledge with management on an ongoing basis for mutual gains purposes.

From the above literature review, we can see that researchers focus on voice definition and its influence of organization. Most studies analyzed the influence factors of voice correlated variables by empirical analysis. After review of past studies, based on game theory, this study tries to establish a static game of complete information between the enterprise and employee, and explore strategy selection of both sides. Moreover, it puts forward appropriate measures in order to achieve win-win development of enterprises and employees.

\section{A Game Model of Enterprise and Employee Voice Behavior}

According to the participants of game model: enterprise and employees' type, each of the parties under the strategy choices and benefits of different strategies of both sides, the paper proposes the following four hypotheses, in pursuit of making a comprehensive analysis under the assumption.

\subsection{The Model Hypothesis}

Hypothesis 1: Participant. There are only two rational participants in this game: enterprise and employees.

Hypothesis 2: The type of game. The enterprise and employees have a common knowledge and action at the same time. That is the game between enterprises and employees which is a static game of complete information, 
and both sides fully understand strategy choice and benefit each other.

Hypothesis 3: The strategy choice. For the employees, they have two choices: "voice" or "silence". Enterprise chooses "incentive" plans for voice behavior through promoting the core competition ability of them; if they prefer immediate benefits, they choose "crackdown" plans for voice behavior.

Hypothesis 4: When employee selects voice, he creates value $R$ for enterprise and employee gets salary $P>0$, employee voice investment cost $C>0$; when enterprise encourage employees voice, if $P$ as "health care" costs to encourage employees voice, enterprise need to pay an extra incentive costs $M>0$, assuming that $M$ is a sunk cost, and from a longer time to consider, we assume $P>M>0$. If employee puts forward some innovative opinions for enterprise, he will receive the extra income $E>0$, except salary $P$, and $E>C>0$.

When employee chooses silence under the strategy of enterprise "incentive" plan, he would get rejected as an alien body among co-workers or team even fired, which leads its income to 0; In this case, the value employee creates for enterprise is 0; When the enterprise takes "crackdown" plans, the silence of the employees still obtain salary $P>0$. In general, this hypothesis does not consider the other factors that affect enterprise and employee benefits, only consider the game under both the employee and the enterprises benefits change.

\subsection{Set the Game Model Up}

Based on above hypothesis, we took a stab at modeling between employee and enterprise about the voice. The payoff matrix is shown below (see Table 1):

In this payoff matrix, employee usually has two results: voice and silence; enterprise has two choices: incentive and crackdown. We assume that no individual has any strict incentive to move away. Using dominant strategy, when enterprise chooses "incentive" plan, employee voice is the best response to the enterprise, and the best respond to enterprise crackdown plan is keeping silence. At the same time, when employee voice, the best response for enterprise is crackdown; and when employee stays silence, it is better for enterprise to choose incentive plan.

Therefore, there is no pure strategy Nash equilibrium, in this case, however there is going to be a mixed strategy Nash equilibrium. Let’s find a mixed strategy Nash equilibrium.

\subsection{Mix Strategy Nash Equilibrium in the Model}

According Table 1, we suppose that $x$ is a randomization over enterprise incentive strategy, and $1-x$ is a randomization when enterprise plays crackdown; $y$ is a randomization when employee choose voice, and employee silence is $1-y$. Then, let's use $\mathrm{SC}=(x, 1-x)$ to be enterprise's mix, and use $\mathrm{Se}=(y, 1-y)$ to be employee's mix.

Expected payoff expression for enterprise:

$$
\begin{aligned}
\mathrm{EU}(\mathrm{SC}, \mathrm{Se}) & =x[y \times(R-P-M)(1-y) \times M]+(1-x)[y \times(R-P)-(1-y) \times P] \\
& =-x M+y R-P-x y P+x P,
\end{aligned}
$$

Expected payoff expression for employee:

$$
\begin{aligned}
\mathrm{EU}(\mathrm{S}, \mathrm{Se}) & =y[x \times(P+E-C)+(1-x) \times(P-C)]+(1-y)[x \times 0+(1-x) \times P] \\
& =x y P+x y E-y C+P-x P,
\end{aligned}
$$

Enterprises to maximize profit of first order optimality conditions: $\partial U / \partial x=0$, we can get:

$$
y^{*}=1-M / P
$$

And, Employee to maximize profit of first order optimality conditions $\partial U / \partial y=0$, we can get:

\begin{tabular}{ccc}
\hline Table 1. Employee voice behavior payoff matrix. & \\
\hline & Employee voice behavior & Employee silence behavior \\
\hline Enterprise "incentive" plan & $R-P-M, P+E-C$ & $-M, 0$ \\
Enterprise "crackdown" plan & $R-P, P-C$ & $-P, P$
\end{tabular}




$$
a^{*}=C /(P+E)
$$

So, we claim that we have found the mixed strategy Nash equilibrium, here is as follows: $x=C /(P+E)$, $y=1-M / P$. Under the mixed strategy Nash equilibrium, enterprise using the strategy incentive with some probability $C /(P+E)$, and using the strategy crackdown with some probability $1-C /(P+E)$; employee using the strategy voice with some probability $1-M / P$, and using the strategy silence with some probability $M / P$.

\section{Factor Analysis of Employee Voice Behavior}

First, When other conditions did not change, $M$ is inversely proportional to $y^{*}$, that is, the higher the cost of enterprise incentive is, the less willing to encourage employee voice behavior are, so the probability of employee choose voice $y^{*}$ is smaller. Thus, we can see the extra cost companies spend to employees' voice is one factor of influencing enterprises and employees of the game.

Second, When other conditions are unchanged, $P$ is direct proportional to $y^{*}$, that is, the higher the cost of enterprise pay for salary is, the more willing to encourage employee voice behavior are, so the probability of employee choose voice $y^{*}$ bigger. Thus, we can see the salary paid to influence corporate enterprises and employees' game.

Third, When other conditions unchanged, $C$ is direct proportional to $a^{*}$, that is, the higher the cost of employee voice investment is, enterprise encourage voice cost is lower, then the enthusiasm of enterprises to encourage voice $a^{*}$ is higher. Thus, we can see employee voice investment cost will affect its behavior.

Last but not least, When other conditions unchanged, $P$ and $E$ is inversely proportional to $a^{*}$ respectively, that is, the more payoff from the salary $P$ and extra income of voice behavior $E$, the greater probability of employee choose voice, and enterprise willing to encourage voice lower, Thus, we can see employee receive the extra income from voice will affect its behavior.

In summary, the additional cost of enterprise incentive voice behavior, companies paid salary, employee voice investment, and employee receive the extra income from voice etc. All of them have a significant impact on employee voice behavior.

\section{General Discussion}

Domestic and scholar who are coming from home and abroad have gained some research achievements in the field of voice, and in this paper, we take a further step to analyze the process of employee voice behavior, and hope to provide some valuable references for the enterprise human resources management practice.

\subsection{For Employee}

Whether employees have opportunities to express their views in enterprises and it will have a positive impact or a negative impact while providing opportunities for employee voice, it almost depends on what employee perceive about the motivation of this kind of opportunity the company and managers provide. Employee who perceives the information will has a mental game. If the employee thinks voice is small in risk and gains big profit, they have strong motives and will select voice behavior, on the contrary, they will choose safe ways to respond keeping silent. In addition, the identity of trust is a kind of more stable high levels of trust, the trust based on the company's identity is not necessarily clear to return, but in response to collective norms, to achieve collective goals, or common preference for employees mutual recognition. Therefore, building mutual trust of employees and the enterprise, it will strengthen communication and reduce or eliminate the psychological alert, so employees would l actively participate in voluntary and put forward reasonable proposals, contributing to the development of collective learning and service teams or departments, and enhance investment in degrees.

\subsection{For Enterprise}

Organizations should create effective smooth environment for employee voice. Voice is a kind of communication from the top to the button, creating first-class communication platform for employee, and also is an effective ways to receive information about each other, reduce bad feelings and spread and influence other employee. In enterprise, it must have a fast and direct communication platform and employee has a main way to promote 
own views. Take staff suggestion box as an example, many people want to participate but finally fail to do so because they cannot do it anonymously. For this reason, the suggestions box serves this purpose; What's more, Holding regular meetings or talking to people in the organization; Distributing a questionnaire before or after some key projects etc. These are good ways. Except for voice platform, the effective feedback in time conscientiously is also very important because it directly affects the next time employees voice will. Managers should be willing to take advice in mind, carefully listen to employee recommendations and opinions admonition to establish positive and effective feedback and tracking mechanisms, regardless of whether the voice is constructive or not. Employee voice behavior should be treated with respect and encouragement.

Create employee voice incentive system. In order to improve employee voice intention, enterprise usually encourage employee voice behavior by raising wages. However, according to the analysis above, we find that high wage does not necessarily lead to more voice behavior, so in order to arouse the enthusiasm and initiative of employee voice, decrease the cost of enterprise pay an extra incentive, it is very important to create a good employee voice incentive system. In such incentives, if the voice content have a positive role in promoting company development, it should offer appropriate awards to encourage its next voice behavior, or you can link constructive voice to performance appraisal of employees, thus it is contributing to positive thinking that employees see the benefits of the proposed initiative which inspire more people to participate in voice. Once this reciprocal, self-interest driving and voluntary incentive mechanism is widely established, and it will bring a wider and deeper employee voice behavior.

Build a harmonious atmosphere in the organization. Organizational climate will directly affect employees' behavior and attitude, and ultimately affect the company's growth and development, so building a good organizational climate to improve employee voice is of an important significance. Good organizational climate should make employee feel few bureaucratic and regulatory restrictions in organization. Exchanges between peers, and communication between the upper and lower should be unobstructed. Adopting open management and participative leadership can raise psychological empowerment, give correct guidance to employee as perceived opportunities, and build a harmonious voice atmosphere of the organization. With the construction of a harmonious atmosphere, the additional costs the enterprise spends in motivating employee voice will be greatly reduced, so as to realize win-win development enterprise and the employees.

\section{Conclusions}

As a measure to improve organizational operations, employee voice behavior has existed since ancient times. In order to encourage employees to come out with more creative generate ideas and opinions, organization managers can not shirk responsibility. Therefore, according to this paper discussed, it comes to a conclusion that through the voicing variety mechanisms and wards on ways to encourage employees, first-class communication platform can be created and the voice atmosphere can be built. Especially as a manager, he or she should enhance the voice of encouragement, openness and responsiveness, they must have a broad mind solicit opinions, but also have the ability to deal effectively with the recommendations. Meanwhile, the employee should also take their own measures, such as to improve their understanding of the behavior of voice, and enhanced corporate identity and trust with enterprise. Then, they can achieve double win.

From the perspective of game theory, this paper has established a static game of complete information between enterprise and the employee. The above discussion shows that four factors have a significant impact on employee voice behavior (the additional cost, salary, investment, and extra income), it could be helpful for enterprise. Nevertheless, there are still many shortcomings in this paper. This research only considers two players and the condition in the complete information game, ignoring lots of other possibilities in this matter. In the future, researcher could consider other players, e.g. co-worker etc., or use the dynamic game model and other analytical methodologies in the progress of voice behavior.

\section{References}

[1] Van Dyne, L.V., Ang, S. and Botero, I.C. (2003) Conceptualizing Employee Silence and Employee Voice as Multidimensional Constructs. Journal of Management Studies, 40, 1359-1392. http://dx.doi.org/10.1111/1467-6486.00384

[2] LePine, J.A. and Van Dyne, L.V. (1998) Predicting Voice Behavior in Work Groups. Journal of Applied Psychology, 83, 853-868. http://dx.doi.org/10.1037/0021-9010.83.6.853

[3] Detert, J.R. and Burris, E.R. (2007) Leadership Behavior and Employee Voice: Is the Door Really Open? Academy of 
Management, 50, 869-884. http://dx.doi.org/10.5465/AMJ.2007.26279183

[4] Morrison, E.W. (2011) Voice and Silence within Organizations: Literature Review and Directions for Future Research. Academy Management. Ann., 5, 373-412.

[5] Liang, J., Farh, C.I.C. and Farh, J.L. (2012) Psychological Antecedents of Promotive and Prohibitive Voice: A TwoWave Examination. Academy Management, 55, 71-92. http://dx.doi.org/10.5465/amj.2010.0176

[6] Ashford, S.J., Sutcliffe, K. and Christianson, M.K. (2009) Peaking up and Speaking out: The Leadership Dynamics of Voice in Organizations. Voice and Silence in Organizations, 175-202.

[7] Wang, Y. and Hsieh, H. (2013) Organizational Ethical Climate, Perceived Organizational Support, and Employee Silence: A Cross-Level Investigation. Human Relations, 66, 783-802. http://dx.doi.org/10.1177/0018726712460706

[8] Wang, L.P. and Chen, Y. (2012) The Analysis of Employee Voice Based on the Game Theory. Forecasting, 6, 7-12.

[9] Freeman, R. and Lazear, E. (1995) An Economic Analysis of Works Councils. In: Rogers, J. and Streeck, W., Eds., Works Councils: Consultation, Representation, and Cooperation in Industrial Relations, University of Chicago Press, Chicago, 27-50. 